years. The mean disease duration was $12.65 \pm 9.49$ years. The clinical presentation of SpA was peripheral in 61 cases and axial in 118 cases. The mean disease scores activity was: BASDAI: $3.94 \pm 2.046$ and ASDASCRP: $2.75 \pm 1.05$. The mean BASFI was $4.17 \pm 2.7$

SP changes were observed in 31 patients: score $1(n=14)$, score $2(n=8)$, score 3 $(n=8)$ and score $4(n=4)$. Sex ratios $M / F$ were 2.1 and 1.65 in $G 1$ and $G 0$, respectively $(p=0.23)$. No statistically significant differences were reported between the two groups $\mathrm{G0}$ and $\mathrm{G} 1$ : mean age ( 40.48 vs. $43.45, \mathrm{p}=0.324)$, mean disease duration (11.19 vs. 14.45, $p=0.218$ ), mean BASDAI (3.8 versus $3.9, p=0.850$ ), mean ASDAS-ESR (3.09 vs. 2.55, $\mathrm{p}=0.113$ ) and mean BASFI (3.76 versus 4.96, $p=0.06$ ) respectively. In $G 1$, nine patients had hip involvement $(p=0.203)$. Enthesitis was more common in patients with SP changes $(p=0.02)$

Conclusion: In our study, the presence of enthesitis was associated with SP changes. Surprisingly, age and disease duration did not influence SP changes (1). REFERENCES:

[1] Kang Y, Ahn JM, Lee E, Lee JW, Kang HS. Active inflammatory changes around the pubic symphysis in patients with axial spondyloarthritis: Magnetic resonance imaging characteristics and association with clinical factors. Eur $\mathrm{J}$ Radiol. mars 2020;124:108802.

Disclosure of Interests: None declared.

DOI: 10.1136/annrheumdis-2021-eular.4013

\section{POS1014 \\ CENTRAL SENSITIZATION HAS MAJOR IMPACT ON QUALITY OF LIFE IN PATIENTS WITH AXIAL SPONDYLOARTHRITIS}

S. Kieskamp ${ }^{1}$, D. Paap ${ }^{1}$, M. Carbo ${ }^{1}$, F. Wink ${ }^{2}$, R. Bos ${ }^{2}$, H. Bootsma ${ }^{1}$, S. Arends ${ }^{1}$, A. Spoorenberg ${ }^{1}$ on behalf of Groningen Leeuwarden Axial Spondyloarthritis (GLAS). ${ }^{1}$ University Medical Center Groningen, Rheumatology and Clinical Immunology, Groningen, Netherlands; ${ }^{2}$ Medical Center Leeuwarden,

Rheumatology, Leeuwarden, Netherlands

Background: Maintaining optimal health-related quality of life (QoL) is the ultimate goal of treatment in axial spondyloarthritis (axSpA). Chronic pain has a large potential impact on QoL. Central sensitization (CS) may explain part of the chronic pain in axSpA. However, the role of central sensitization (CS) herein has only been studied to a limited degree and current axSpA guidelines pay little attention to identification and treatment of CS.

Objectives: To explore the relationship between CS and QoL in axSpA.

Methods: Consecutive outpatients with axSpA from the Groningen Leeuwarden Axial Spondyloarthritis (GLAS) cohort were included. CS was assessed with the Central Sensitization Inventory (CSI; 0-100), QoL with the AS Quality of Life questionnaire (ASQoL; 0-18) and disease activity with the AS Disease Activity Score (ASDAS ${ }_{\text {PRP }}$ ). A high probability of CS was defined as CSI score $\geq 40$ and active disease as ASDAS $_{\text {CRP }}$ score $\geq 2$. 1 . Patient characteristics and clinical assessments were compared between groups with CSI score $<40$ and $\geq 40$.(1) Multivariable regression analysis was conducted to investigate the relationship between CSI and ASQoL scores, correcting for potential confounders.

Results: Of the 178 axSpA patients with available CSI score, 149 completed the ASQoL. Mean age of the 178 included patients was $47.4 \pm 14.1$ years, 78 (44\%) were female, mean symptom duration was $21.4 \pm 13.6$ years and $88(52 \%)$ were using bDMARDS. Mean CSI score was $38.0 \pm 14.1$, mean ASQoL $6.0 \pm 5.3$ and mean ASDAS $2.1 \pm 1.0$. CSI score $\geq 40$ was significantly associated with higher mean ASQoL (9.7 vs. 3.3), higher mean ASDAS $_{\text {CRP }}$ (2.6 vs. 1.7), female gender $(60 \%$ vs. $29 \%)$ and more often entheseal involvement (61\% vs. $26 \%$ ) (Table 1$)$

Table 1. Selection of patient characteristics, disease activity and clinical outcome variables for patients with axSpA, divided in subgroups for CSI score with a cutoff point of 40 .

\begin{tabular}{|c|c|c|c|}
\hline Characteristics & $\begin{array}{l}\text { All patients } \\
\mathrm{n}=178\end{array}$ & $\begin{array}{c}\mathrm{CSI}<40 \\
\mathrm{n}=98(55 \%)\end{array}$ & $\begin{array}{c}C S I \geq 40 \\
n=80(45 \%)\end{array}$ \\
\hline Age (years) & $47.4 \pm 14.1$ & $48.7 \pm 15.0$ & $45.8 \pm 12.7$ \\
\hline Female & $78(44)$ & $27(29)$ & $44(60)^{*}$ \\
\hline Symptom duration (years) & $21.4 \pm 13.6$ & $21.5 \pm 13.5$ & $21.2 \pm 13.8$ \\
\hline HLA-B27+ & $133(79)$ & $70(79)$ & $54(79)$ \\
\hline Smoker & $45(27)$ & $28(32)$ & $15(23)$ \\
\hline BMI $\left(\mathrm{kg} / \mathrm{m}^{2}\right)$ & $26.7 \pm 5.0$ & $26.2 \pm 4.4$ & $27.5 \pm 5.8$ \\
\hline Completed higher education ${ }^{1}$ & $81(71)$ & $48(70)$ & $34(76)$ \\
\hline Biological use & $88(52)$ & $49(52)$ & $39(51)$ \\
\hline $\mathrm{RDCl}(0-9)$ & $0.0(0.0-1.0)$ & $0.0(0.0-1.0)$ & $0.0(0.0-1.8)$ \\
\hline Peripheral arthritis ${ }^{2}$ & $10(6)$ & $5(6)$ & $5(8)$ \\
\hline Entheseal involvement ${ }^{3}$ & $64(40)$ & $23(26)$ & $38(61)^{*}$ \\
\hline ASDAS $_{\text {CRP }}$ & $2.1 \pm 1.0$ & $1.7 \pm 0.9$ & $2.6 \pm 1.0^{\star}$ \\
\hline CRP $(\mathrm{mg} / \mathrm{ml})$ & $2.9(1.1-6.8)$ & $2.6(1.1-6.0)$ & $3.6(1.4-7.0)$ \\
\hline ASQoL $(0-18)$ & $6.0 \pm 5.3$ & $3.3 \pm 3.6$ & $9.7 \pm 4.9^{*}$ \\
\hline CSI $(0-100)$ & $38.0 \pm 14.1$ & $28.0(23-34)$ & $50.0(43.0-56.0)$ \\
\hline
\end{tabular}

Values are $\mathrm{n}(\%)$, mean \pm SD or median (IQR).1 International Standard Classification of Education (ISCED) level >4; 2Swollen Joint Count $>0$; 3Maastricht Ankylosing Spondylitis Enthesitis Score $>0$. ${ }^{*} p<0.001$. ASDASCRP: Ankylosing Spondylitis Disease Activity Score; ASQoL: Ankylosing Spondylitis Quality of Life questionnaire; CRP: C-reactive protein; CSI: Central Sensitization Inventory; RDCI: Rheumatic Disease Comorbidity Index.
Patients with low ASDAS ${ }_{\text {PRP }}(<2.1)$ and also low CSI score $(<40)$ showed good QoL (median ASQoL 1.1). Patients with low ASDAS ${ }_{C R P}$ combined with high CS score $(\geq 40)$ and patients with high ASDAS $_{\text {RP }}(\geq 2.1)$ combined with low CS score reported worse QoL (median ASQoL 5.6 and 4.1, respectively). Patients with high ASDAS ${ }_{\mathrm{CRP}}$ and also high CSI score reported the worst QoL (median ASQoL 12.0). (Figure 1).
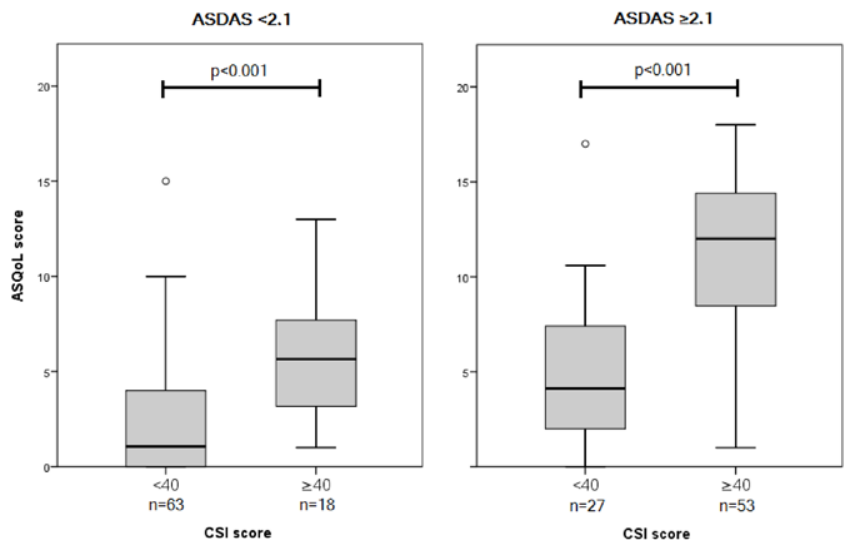

Figure 1. ASQoL score in patients with axSpA with $\mathrm{CSI}$ score $>40$ and $<40$, divided for ASDAS $_{\text {CRP }}$ (cutoff 2.1)

Additionally, in univariable analysis, the CSI score explained a large proportion of the variation of the $A S Q \circ L\left(R^{2}=0.46\right)$. This association remained significant after correction for ASDAS $_{\mathrm{CRP}}$, gender, symptom duration, entheseal involvement, smoking status, BMI category, educational level and comorbidities in multivariable analysis (CSI $\mathrm{p}<0.001)$.

Conclusion: In daily clinical practice, CS seems strongly related to patient-reported QoL in patients with long-term axSpA.

REFERENCES:

[1] Neblett R et al. J Pain. 2013;14:438-45.

Acknowledgements: The authors would like to thank all patients who participated in the GLAS cohort. Furthermore, the authors wish to acknowledge Mrs B. Burmania, Mrs. B. Hollander, Mrs. S. Katerbarg, Mrs. S. Lange, Mrs. E. Markenstein, Mrs. R. Rumph and Mrs. M. de Vries-Veldman for their contribution to clinical data collection.

Disclosure of Interests: Stan Kieskamp: None declared, Davy Paap: None declared, Marlies Carbo: None declared, Freke Wink Consultant of: Abbvie, Reinhard Bos: None declared, Hendrika Bootsma Grant/research support from: Roche, Suzanne Arends Grant/research support from: Pfizer, Anneke Spoorenberg Consultant of: Abbvie, Pfizer, MSD, UCB, Lilly, Novartis, Grant/research support from: Abbvie, Pfizer, UCB, Novartis.

DOI: 10.1136/annrheumdis-2021-eular.4035

\section{POS1015 ANTI-TNF DRUGS AND CARDIOVASCULAR EVENTS IN PATIENTS WITH SPONDYLOARTHRITIS}

C. W. S. Chan ${ }^{1}$, P. H. LI ${ }^{1}$, C. S. Lau ${ }^{1}$, H. Y. Chung ${ }^{1} .{ }^{1}$ The University of Hong Kong, Queen Mary Hospital, Hong Kong, Division of Rheumatology and Clinical Immunology, Department of Medicine, Hong Kong, Hong Kong (SAR)

Background: Cardiovascular (CVS) diseases are the leading cause of death worldwide and patients with rheumatic diseases have an increased CVS risk including stroke and myocardial infarction (MI) (1-3). CVS risk factors and CVS events are common in SpA (4). Delineating the CVS risk and the association with medications in patients with $\mathrm{SpA}$ would be useful.

Objectives: The objective of this study was to delineate the CVS risk and the association with medications in patients with SpA.

Methods: Patients with $\mathrm{SpA}$ and patients with non-specific back pain (NSBP) were identified in rheumatology and orthopedics clinics respectively. Clinica information and CVS events were retrieved. Incidence rates were calculated. Association analysis was performed to determine the CVS risk of SpA and other modifiable risk factors.

Results: A total of 5046 patients (SpA 2616 and NSBP 2430) were included from eight centers. Over 56484 person-years of follow-up, 160 strokes, $84 \mathrm{Ml}$ and 262 major adverse cardiovascular events (MACE) were identified. Hypercholesterolemia was more prevalent in SpA (SpA 34.2\%, NSBP 28.7\%, P<0.01). Crude incidence rates of stroke and $\mathrm{MI}$ were higher in SpA patients. SpA was associated with a higher risk of MACE $(\mathrm{HR} 1.66,95 \% \mathrm{Cl} 1.22-2.27, \mathrm{P}<0.01)$ and cerebrovascular events ( $\mathrm{HR} 1.42,95 \% \mathrm{Cl} 1.01-2.00, \mathrm{p}=0.04)$. The use of anti-tumor necrosis factor (TNF) drugs was associated with a reduced risk of MACE (HR $0.37,95 \% \mathrm{Cl} 0.17-0.80, \mathrm{P}=0.01)$ and cerebrovascular events (HR $0.21,95 \% \mathrm{Cl}$ $0.06-0.78, P=0.02$ ). 